\title{
A Two-year Retrospective Study of Emergency Dental Treatments at Mureș County Emergency Hospital
}

\author{
Kinga Dörner', Melinda Kis¹, Emese Markovics¹, Orsolya Birta1, Zsuzsa Koszta1, Cristian Boeriu², \\ Hajnal Vass ${ }^{3}$, Melinda Székely4 \\ 1 Department of Removable Prosthetic Dentistry, Faculty of Dental Medicine, University of Medicine and Pharmacy, Tîrgu Mureș, \\ Romania \\ 2 Department of Anesthesiology and Intensive Care Medicine (II) and Emergency Medicine, Faculty of General Medicine, University of \\ Medicine and Pharmacy, Tîrgu Mureș, Romania \\ ${ }^{3}$ Department of Anesthesiology and Intensive Care Medicine (II) and Emergency Medicine, Mureș County Emergency Hospital, Tîrgu \\ Mureș, Romania \\ 4 Department of Morphology of Teeth and Dental Arches; Technology of Dental Prostheses and Dental Materials, Faculty of Dental \\ Medicine, University of Medicine and Pharmacy, Tîrgu Mureș, Romania
}

\section{CORRESPONDENCE}

\section{Melinda Kis}

Str. Gheorghe Marinescu nr. 50

540139 Tîrgu Mureș, Romania

Tel: +40 265215551

E-mail: melinda.nagy.mail@gmail.com

\section{ARTICLE HISTORY}

Received: 3 March, 2017

Accepted: 8 March, 2017
Kinga Dörner • Str. Gheorghe Marinescu nr. 50 , 540139 Tîrgu Mureș, Romania, Tel: +40 265215551 Melinda Kis • Str. Gheorghe Marinescu nr. 50, 540139 Tîrgu Mureș, Romania, Tel: +40 265215551

Emese Markovics • Str. Gheorghe Marinescu nr. 50, 540139 Tîrgu Mureș, Romania, Tel: +40 265215551 Orsolya Birta $\cdot$ Str. Gheorghe Marinescu nr. 50, 540139 Tîrgu Mureș, Romania, Tel: +40 265215551 Zsuzsa Koszta • Str. Gheorghe Marinescu nr 50 540139 Tîrgu Mureș, Romania, Tel: +40 265215551 Cristian Boeriu - Str. Gheorghe Marinescu nr. 38 , 540139 Tîrgu Mureș, Romania, Tel: +40 265217235 Hajnal Vass • Str. Gheorghe Marinescu nr. 38, 540139 Tîrgu Mureș, Romania, Tel: +40 265217235

Melinda Székely • Str. Gheorghe Marinescu nr. 50, 540139 Tîrgu Mures, Romania, Tel: +40 265215551

\begin{abstract}
Background: Emergency dental care is provided at the Mures County Emergency Hospital in Tîrgu Mures since February 2012, however, there is little information available regarding its activity. Therefore, the aim of the study was to evaluate the prevalence and diagnosis of denta emergency cases treated in this dental office over the first two years. Material and methods This two-year retrospective study was based on the analysis of patients' dental records who were treated at the Dental Office of the Mureș County Emergency Hospital in Tîrgu Mureș. Results: In the first year 5567 patients were treated, whereas in the second year their number was significantly higher, 7213 patients. Pulp infections presented the highest prevalence in both years: $32.38 \%$ and $34.74 \%$, respectively. Compared to the first year $(n=1,803)$ significantly more cases $(p=0.001)$ were treated with this diagnosis in the second year $(n=2,506)$. Periodontal infections were significantly more frequent $(p<0.001)$ in the second year compared to the first -951 cases (13.18\%) vs. 681 (12.23\%) cases. Conclusions: The main reasons of emergency dental treatments were dental and periodontal infections. The results suggest that dental care is unaffordable to socially disadvantaged persons, and this fosters radical treatment of pain in this free of charge $24 \mathrm{~h}$ dental emergency office.
\end{abstract}

Keywords: emergency dental office, retrospective study, dental diagnosis

\section{INTRODUCTION}

Dental pain is generally caused by caries, deep or defective restorations, or trauma. ${ }^{1}$ The definition of "dental emergency" provided by the American Dental Association includes acute dental pain, and in the vast majority of cases the origin 
of the pain is endodontic. ${ }^{2}$ Dental emergencies include reversible and irreversible pulpitis, interappointment endodontic emergencies, dental trauma, periapical and periodontal abscess, cellulitis, pericoronitis and cracked tooth syndrome. ${ }^{1}$ The dense nerve network of the head and neck region is primarily responsible for the severity and intensity of the pain, which causes stress for both the patient and the clinician, and requires an immediate diagnosis and accurate treatment. ${ }^{2}$ When establishing the therapeutic choice in the dental practice, the dentist will have to take two main aspects into account: the magnitude of the dental intervention and the potentially associated systemic pathology and its compensation level, which can allow or prevent safe dental therapy. ${ }^{3}$

A thorough review of the medical and dental histories, including a detailed description of the chief complaint, is still an essential initial step in the diagnostic process. Questions to be resolved include a history of chronic painful conditions such as headaches, neuralgia and temporal-mandibular dysfunction. Symptoms associated with these chronic conditions could be confused with an endodontic problem and may predispose a patient to long-term pain. The value of the patient-doctor dialogue cannot be over-estimated. ${ }^{4}$

The Emergency Dental Office of the Mureș County Emergency Hospital in Tîrgu Mureș functions in the Mobile Emergency Service for Resuscitation and Extrication (MESRE) according to the Ordinance No. 1706/October 2, 2007 of the Ministry of Health regarding the administration and organization of units and departments for receiving emergencies. Due to multiple requests, on February 1, 2012 the MESRE Emergency Dental Office of Tîrgu Mureș was established as a free $24 \mathrm{~h}$ service. ${ }^{5}$

The aim of this study was to evaluate the prevalence and diagnosis of dental emergency cases treated in the Dental Office of the Mureș County Emergency Hospital in Tîrgu Mureș over the first two years since its establishment.

\section{MATERIAL AND METHODS}

The study was approved by the Research Ethics Committee of the University of Medicine and Pharmacy of Tîrgu Mureș (No. 17/March 10, 2014). In this retrospective twoyear study the non-personal data of patients treated at the MESRE Emergency Dental Office Tîrgu Mureș were processed statistically and evaluated.

The methodology of the study was retrospective and descriptive, and was based on the analysis of the records of patients examined and treated at the Emergency Dental Office of the Mureș County Emergency Hospital in Tîrgu Mureș between February 1, 2012 and February 1, 2014. The patients who attended this unit were registered in the databases of the emergency dental offices and in the examination registry, after having presented their ID card. Patients from other sections who were transferred to this unit were previously admitted to the County Emergency Hospital with dental problems, at times requiring inter-disciplinary examination in order for the dental emergency procedures to be performed.

The medical examination consisted of an external and internal oral examination with artificial light at the dental unit, with a special examination kit. No dental X-rays were performed in the studied unit, thus the emergency diagnosis was based on the internal oral examination and the history of the condition.

Patients with traumas or conditions that did not fall in the competence of the dentists providing emergency services in Tîrgu Mures were guided to the Oro- and Maxillofacial Surgery Clinic, and those for whom the treatment needed continuance, to the Walk-in Clinic for adults and children, functioning within the County Emergency Hospital from Tîrgu Mureș, according to the agreements signed between the three centers.

The non-personal data has been taken from the dental records and the databases of the practice and were classified according to the patients' gender (male/female) and diagnoses. The objective of this study was to determine the prevalence and the characteristics of dental problems for which emergency interventions were requested by the subjects, by including the above mentioned items in accordance with the months of the year and the two studied years, respectively.

The obtained data were introduced in Microsoft Excel sheets, and the statistical analyses were carried out with the IBM SPSS Statistic Data Editor 16 software. We used Student's t-test, ANOVA and the Pearson correlation, with a confidence interval of $95 \%$. The $p$ values lower than 0.05 were considered significant from a statistical point of view. ${ }^{6}$

\section{RESULTS}

During the two years from its establishment, $12,780 \mathrm{pa}-$ tients were treated at the Emergency Dental Office in Tîrgu Mureș (Figure 1). In the first year there were 5567 patients, whereas in the second year their number was significantly higher, 7213 patients $(\mathrm{p}<0.05)$. There were significantly more female patients than males - 7846 (61.39\%)females compared to 4934 (38.61\%) males.

The diagnoses collected through the two-year period were grouped according to the conditions: pulp infections presented the highest prevalence, 4,309 (33.72\%) 


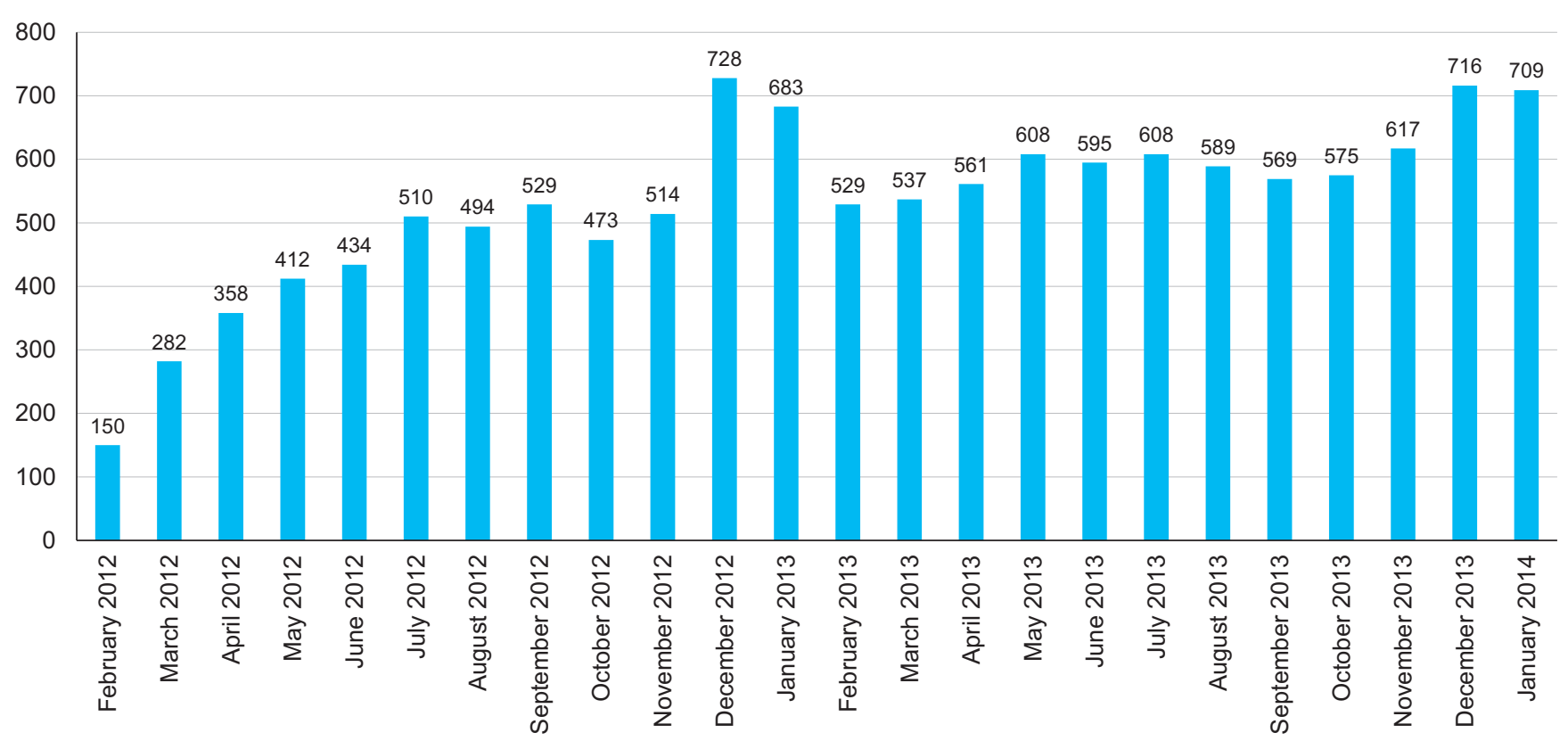

FIGURE 1. The distribution of total number of patients treated in the Emergency Dental Office in Tîrgu Mureș during the studied period

cases, followed by root remnants with 1,675 (13.11\%) cases, dental caries with $1,665(13.03 \%)$ cases, periodontal infections with $1,632(12.77 \%)$ cases, dental abscesses with $1,369(10.71 \%)$ cases, other periodontal diseases with $763(5.97 \%)$ cases, and post-extraction conditions with $418(3.27 \%)$ cases. The rest of the diagnosed cases, such as pericoronitis, mixed dentition disorders, lesions of the oral mucosa, nervous disorders, trauma and dental outbreaks, amounted to $0.05-2 \%(\mathrm{n}=7-198)$ (Figure 2$)$.
No significant differences were observed regarding dental caries in the studied period. Pulp infections presented the highest prevalence in both years, $32.38 \%$ and $34.74 \%$, respectively. Compared to the first year $(n=1,803)$, significantly more cases $(\mathrm{p}=0.001)$ were treated with this diagnosis in the second year $(\mathrm{n}=2,506)$. Periodontal infections were also significantly more frequent $(\mathrm{p}<0.001)$ in the second year with 951 (13.18\%) cases compared to the $681(12.23 \%)$ cases in the first year. No significant differ-

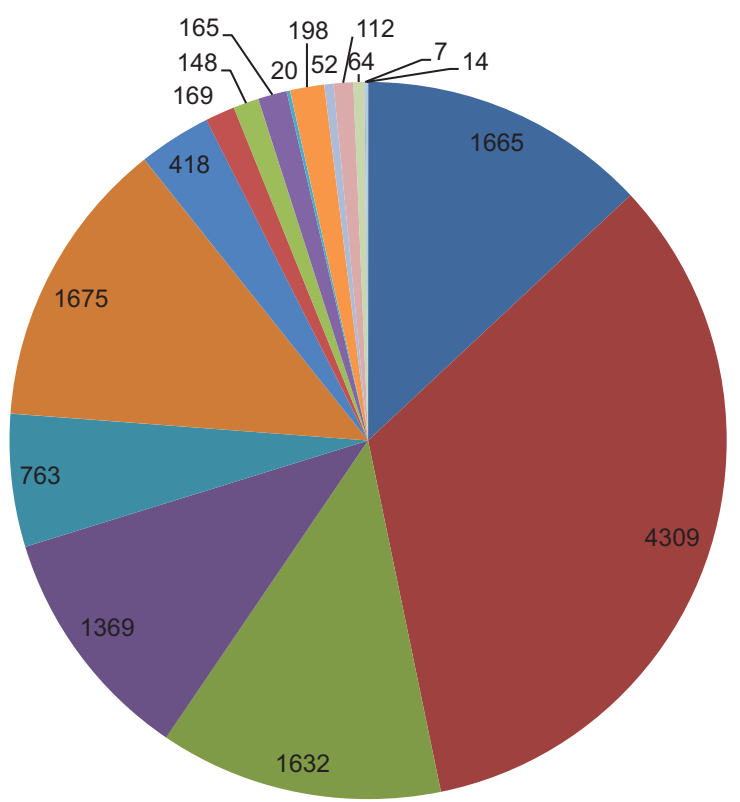

I. Coronary lesions and destructions
II. Pulp infections
-III. Periodontitis
-IV. Abcess
V. Periodontal disease
VI. Root remnant
VII. Postextraction conditions
VIII. Pericoronaritis
IX. Mixed dentition affections
X. Lesions of oral mucosa
XI. Nervous affections
XII. Traumatisms
XIII. Dental screening
XIV. Decemented prosthetic
XV. Other affections
XVI. ATM affections
XVII. Other causes

FIGURE 2. Summary of the diagnoses during the two year period 
TABLE 1. The most frequently observed diagnoses during the study period

\begin{tabular}{lccccc}
\hline Diagnosis & \multicolumn{2}{c}{ First year } & \multicolumn{2}{c}{ Second year } & p value \\
\hline Dental caries & $\mathrm{n}=806$ & $14.47 \%$ & $\mathrm{n}=859$ & $11.90 \%$ & 0.524 \\
Pulp infections & $\mathrm{n}=1803$ & $32.38 \%$ & $\mathrm{n}=2506$ & $34.74 \%$ & 0.001 \\
Periodontal infections & $\mathrm{n}=681$ & $12.23 \%$ & $\mathrm{n}=951$ & $13.18 \%$ & $<0.001$ \\
Root remnants & $\mathrm{n}=692$ & $12.43 \%$ & $\mathrm{n}=983$ & $13.62 \%$ & 0.001 \\
\hline
\end{tabular}

ences were observed regarding dental caries in the studied period. Table 1 presents a summary of the most frequently observed diagnoses during the study period.

\section{DISCUSSION}

Fear of the pain associated with endodontic treatment remains a problem for patients and dentists. Our culture and the media reinforce the belief that endodontics means pain. The result can be a patient's refusal to have endodontic treatment, and these patients frequently opt instead for an extraction. ${ }^{7}$ Avoidance of dental treatment due to dental fear and anxiety has been associated with significant deterioration of oral and dental health. Even at the diagnostic stage, severe anxiety may confuse the process. ${ }^{8}$

Individuals without a regular medical care are less likely to attend the necessary health services. Similarly, individuals without basic dental care may use the hospital's dental emergency departments or physicians' offices for treatment of their dental problems. ${ }^{9-11}$

Analyzing the number of patients per month in the first and the second year, one can observe that from the establishment of the Emergency Dental Office in Tîrgu Mureș the number of patients showed a linear growth in the first year, whereas in the second year the growth was constant.

The patients' number increased significantly $(\mathrm{p}<0.05)$ from one month to the next. The highest values were observed in December due to the winter holidays, as well as in spring, around Easter, when other dental practices were closed in Tîrgu Mureș. Analyzing the data it was observed that the number of patients who requested an emergency intervention ranged between a minimum of 150 persons and a maximum of 728 persons per month (Figure 1). Throughout the two studied years, the average number of patients who requested emergency dental care per day was 18. The maximum number of examined and treated patients in 24 hours was 46 patients, on December 29, 2013.

By analyzing the diagnostic data established in emergency, it was observed that most frequently, patients appear with pain caused by pulp injuries in $33.72 \%$ of cases ( $\mathrm{n}$
$=4,309)$, followed by root remnants in $13.11 \%(n=1,675)$, coronary lesions and destructions in $13.03 \%(\mathrm{n}=1,665)$ and periodontitis in $12.77 \%$ of cases $(n=1,632)$, followed by dental abscesses in $10.71 \%(n=1,369)$, other periodontal diseases in $5.97 \%(\mathrm{n}=763)$, and post-extraction conditions in $3.27 \%$ of cases $(n=418)$ (Figure 2$)$.

Interpreting the diagnoses established in the group of coronary lesions and destructions, which account for $13.03 \%$ of the conditions seen, the highest frequency was found in case of deep caries, which accounted for $60 \%$ of the registered cases $(n=992)$. The cause of several dental complaints is tooth caries or bacterial disease of the teeth. Tooth decay does not cause any pain or discomfort in the early stages, such as incipient caries, however, once the decay reaches the dentine, it becomes painful. One of the symptoms of tooth decay may be pain felt after consuming sweet, hot or cold food and drinks. ${ }^{12}$ The remaining $40 \%$ of the group of coronary lesions and destructions consists of decay in $28 \%(\mathrm{n}=472)$, sensitive teeth in $7 \%(\mathrm{n}=110)$ and pulp hyperemia in $5 \%$ of cases $(n=90)$.

Pulp injuries presented the highest prevalence over the studied period compared to the overall number of diagnoses established, namely $33.72 \%$ of cases $(n=4,309)$. The pain becomes localizable when the pulp inflammation is in a sufficiently advanced stage so as to involve periapical tissues, and the tooth becomes painful to touch or pressure. It was observed that $50 \%(n=2,169)$ of pulp injuries were severe pulpitis. A tooth with acute pulpitis is extremely sensitive to temperature oscillations, so cold air is enough to trigger the pain. ${ }^{13}$

The prevalence of gangrene in the studied unit was $38 \%$ ( $\mathrm{n}=1,638)$, which is a dental disease that appears when a tooth is left untreated and anaerobic putrefaction bacteria decompose the necrotic tissue. Putrefaction bacteria cause the accumulation of gases, leading to pressure in the tooth, which eventually causes severe pain. Trepanation often eases the pain, as putrefaction gases, pus and secretions can be eliminated from the root canal. ${ }^{14}$ Purulent pulpitis accounted for $11 \%$ of cases $(n=455)$, while chronic pulpitis, which is often without any symptoms and necrosis, was represented in a very small percentage. 
In the group of periodontitis accounting for $12.77 \%$ of cases $(n=1,632)$ of the overall diagnoses established, acute apical periodontitis appeared in $91 \%(n=1,478)$ of the cases, while chronic apical periodontitis accounted for a much smaller percentage of $9 \%(\mathrm{n}=154)$, appearing following a bacterial infection such as gangrene, or after trau$\mathrm{ma}$, without involving bacteria. The infection diffuses into the jawbone through the apical foramen. The diagnosis is confirmed by a negative sensibility test. Therapy consisted in trepanation and root treatment.

The distribution of abscesses as a diagnosis in the $10.71 \%$ of cases $(n=1,369)$ revealed that $65 \%(n=894)$ of these conditions were mediastinal abscess, followed by cellulitis with $15 \%(n=209)$ and periodontal abscess with a frequency of $12 \%(n=157)$, as well as periapical cyst in $8 \%$ of cases $(n=107)$.

By analyzing the prevalence of periodontal disease $(5.97 \%, \mathrm{n}=763)$ through the established diagnosis, it was observed that there was a significantly higher number involving parodonthotic teeth $(98 \%, \mathrm{n}=744)$. Teeth with a high level of mobility were extracted. During each tooth extraction an anamnesis was carefully taken with regards to the patients' medication, given the high number of hypertensive patients, patients with spasm or cardiac ischemia or strokes where anticoagulation treatment is administered. ${ }^{15}$ In such cases the intervention was performed after consulting the specialist and/or modifying or interrupting the treatment by the patient's cardiologist. ${ }^{14,16}$

The collection of data regarding the established diagnosis, the distribution of post-extraction conditions $(3.27 \%$, $\mathrm{n}=418)$ revealed a prevalence of $44 \%(\mathrm{n}=158)$ of postextraction consultations (involving the removal of the suture wires in some cases). In $42 \%(n=173)$ of the reported cases post-extractional alveolitis was found, which is an infectious complication of tooth extraction due to the lack of rigorous asepsis and antisepsis, as well as of postextraction indications. Dry alveolitis is an osteitis located at the level of post-extractional alveolitis, represented by the lysis of the blood clot. The dominating symptom is intense pain appearing 2-3 days after extraction. Treatment includes oral analgesics and irrigation with antiseptic and antibiotic solutions. Usually, full recovery lasts for 3-4 weeks. ${ }^{17}$ Post-extraction hemorrhages, accounting for $14 \%(n=60)$ of post-extraction conditions, appeared due to local and/or general factors, which either inhibit the formation of the clot or enhance its premature lysis. In the case of early post-extractional bleeding (a few hours after extraction), the clots are removed, the tooth socket is thoroughly washed with physiological saline and a gelatin sponge (Gelaspon) is introduced into the tooth socket. It may or may not be associated with thrombin. If necessary, the suture of the post-extractional wound is performed. ${ }^{18}$

Similar studies were conducted in Merseyside, between April 2006 and December 2006, and in south-east Queensland between January 2008 and August 2010. In the first study, the collected information revealed that the most common clinical diagnosis was caries (23.9\%), followed by cavities caused through decay or lost restorations (17.6\%). ${ }^{19}$ In the second study, the main reason for emergency attendance was related to caries $(75 \%)$ and trauma $(8 \%) .20$

This retrospective study has some limitations. It was not possible to evaluate whether the documented diagnoses were accurate, and it was not possible to analyze the appropriateness of the treatments.

\section{CONCLUSIONS}

The great number of patients and the nature of the cases treated at the MESRE Emergency Dental Office of Mures County Emergency Hospital in Tîrgu Mureș revealed the lack of public dental care in this region. The results suggest that dental care is unaffordable to socially disadvantaged persons and this fosters radical treatment of pain in this free of charge $24 \mathrm{~h}$ dental emergency office. The majority of the patients attending the Emergency Dental Office had pain associated with a local infection, such as pulpitis, acute dental infections and dental abscesses. The current study highlighted that there is an insufficient demand for dental care in the studied population. The results suggest that the number of patients' visits to the Emergency Dental Office could be reduced by increased awareness of oral and dental care.

\section{CONFLICT OF INTEREST}

There is no relationship that can lead to any conflict of interests.

\section{ACKNOWLEDGEMENT}

The authors gratefully acknowledge the management of the Mobile Emergency Service for Resuscitation and Extrication Tîrgu Mureș and the team of the Emergency Dental Office for supplying the medical data.

\section{REFERENCES}

1. Farmakis E, Palamidakis F, Skondra F, et al. Emergency care provided in a Greek dental school and analysis of the patients demographic characteristics: a prospective study. Int Dent J. 2016;66:280-286. 
2. Wolcott J, Rossman L, Hasselgren G. Management of Endodontic Emergencies. Pathways of the pulp. 2011;10:40-44.

3. Voroneanu M, Bucur A, lordache N, Bălan H. Urgente medico-chirurgicale în cabinetul de medicină dentară. București: Editura Medicală, 2014; p. 12-13.

4. Nixdorf DR, Moana-Filho EJ, Law AS, et al. Frequency of persistent tooth pain after root canal therapy: a systematic review and meta-analysis. $J$ Endod. 2010:36:224-230

5. Dörner K, Boeriu C, Vass H, Nagy M, Koszta Zs, lurcov R, Székely M. Comparative Study Regarding Activity of Emergency Dental Offices in Tîrgu Mureș and Oradea. Acta Medica Marisiensis. 2015;61:118-121.

6. Măruşteri M. Noțiuni fundamentale de biostatistică: note de curs. Tîrgu Mureş: University Press, 2006; p. 52-59.

7. Rosenberg P. Endodontic pain. Endodontic Topics. 2014;30:75-98.

8. Carr DB, Goudas LC. Acute pain. Lancet. 1999;353:2051-2058.

9. Burt CW, McCaig LF. Trends in hospital emergency department utilization: United States, 1992-99. Vital Health Stat 13. 2001;(150):1-34.

10. Lewis C, Lynch $\mathrm{H}$, Johnston B. Dental complaints in emergency departments: a national perspective. Ann Emerg Med. 2003;42:93-99.

11. Cohen L, Bonito A, Eicheldinger C, et al. Comparison of patient visits to emergency departments, physician offices, and dental offices for dental problems and injuries. J Public Health Dent. 2011;71:13-22.
12. Greenwood M, Corbett I. Dental Emergencies. Chicester, West Sussex: Blackwell Publishing Ltd., 2012; p. 85.

13. Roman I, Bocskay S, Torcătoru A. Patologia și terapia cariei complicate. Endodonție. Tîrgu Mureș: University Press, 2009; p. 41-85.

14. Dörner K, Székely M, Matekovits G. Asistenta de medicină dentară si pacienții aflați sub terapie anticoagulantă - partea a XII-a. Dental Target. 2013:8:45-46.

15. Colojoară C. Curs de reabilitare orală şi urgențe stomatologice. Timișoara: Lito UMFT, 2001; p. 9-76.

16. Blinder $D$. Oral surgical procedures in patients on anticoagulant therapy. JADA. 1966; 130:681-683.

17. Bucur A. Compendiu de chirurgie oro-maxilo-facială. București: Ed. Q Med Publishing, 2009; p. 100-101.

18. Kovács D. Ambuláns szájsebészet. Tîrgu Mureș: University Press, 2002; p. 80-84.

19. Tulip DE, Palmer NO. A retrospective investigation of the clinical management of patients attending an out of hours dental clinic in Merseyside under the new NHS dental contract. Br Dent J. 2008;205:659-664.

20. Wong NH, Tran C, Pukallus M, Holcombe T, Seow WK. A three-year retrospective study of emergency visits at an oral health clinic in southeast Queensland. Aust Dent J. 2012;57:132-137. 